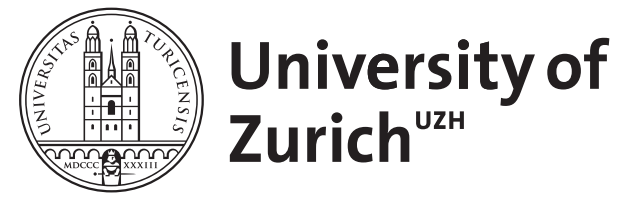

Zurich Open Repository and Archive

University of Zurich

Main Library

Strickhofstrasse 39

CH-8057 Zurich

www.zora.uzh.ch

Year: 2013

The history and philosophy of inflammatory bowel disease

Rogler, Gerhard

DOI: https://doi.org/10.1159/000354676

Posted at the Zurich Open Repository and Archive, University of Zurich

ZORA URL: https://doi.org/10.5167/uzh-92821

Journal Article

Originally published at:

Rogler, Gerhard (2013). The history and philosophy of inflammatory bowel disease. Digestive Diseases, $31(3-4): 270-277$.

DOI: https://doi.org/10.1159/000354676 


\title{
The History and Philosophy of IBD
}

\author{
Gerhard Rogler
}

Keywords: Inflammatory Bowel Disease, Crohn's Disease, Burrill B. Crohn, Ludwig Wittgenstein, Ludwik Fleck, thought-collectives, disease concepts, genetic susceptibility

\section{Address for correspondence:}

Prof. Dr. med. Dr. phil. Gerhard Rogler

Division of Gastroenterology and Hepatology

University Hospital Zürich

Rämistrasse 100

8091 Zürich

Switzerland

gerhard.rogler@usz.ch 


\section{Summary:}

Many interesting statements about Inflammatory Bowel Diseases (IBD) and also Crohn's disease have been made in recent years in journals and scientific meetings. They have influenced our thinking and the perception of the diseases. Among those statements is the notion that IBD are "relatively new diseases", that "IBD is rather a syndrome than a disease" or that with the new insights into pathophysiology, "we will be able to discriminate many different Crohn's diseases based on genetic risk factors". A look into history and philosophy may help to clarify misconceptions and prove that many of those statements are either wrong or misleading. People suffered from symptoms that are suggestive of Crohn's disease centuries before the disease concept evolved in the early $19^{\text {th }}$ century and before Burrill B. Crohn could describe a complex of symptoms he suggested to be a so for non-identified disease. Early concepts on the pathophysiology of $C D$ were not so different to present time theories as it may be assumed. "Pre-ideas" and basic concepts were leading the search for a cause of Crohn's disease and IBD. With respect to pathophysiology we have to accept that most likely we will never come with one unifying concept ("THE cause of IBD") as different scientific schools and think-collectives exist. Therefore, the "classical adaptive immunologists" and the "innate immunologist" as well as scientists focused on barrier function or the microbiome will never completely understand each other and each other's concepts. As for many other diseases several different pathophysiological concepts existed in parallel and will do so in the future as it is impossible to prove the exclusive "truth" of one of the concepts for reasons that will be further discussed below. This means on the other hand that none of the concepts on pathophysiology of IBD we have at present will ever unequivocally be proven to be wrong. 


\section{The History of Inflammatory Bowel Disease - Did IBD exist before Burrill B. Crohn's description of terminal ileitis?}

It does not make sense to say that a disease entity as we understand Crohn's disease now existed before the description by Burrill B. Crohn and colleagues [1]. The intellectual concept of "disease" the way we still know it today has developed in the $19^{\text {th }}$ century [2-4]. The methods of scientific medicine developed in the late $18^{\text {th }}$, the $19^{\text {th }}$ and the early $20^{\text {th }}$ century were necessary to come to a descriptions and definitions that are the basis of our present time medical approach.

However, illnesses did exist before we could perceive them the way we do this nowadays and before we could recognize symptoms as being connected by one causative agent our occurring together in a characteristic pattern. A complex of symptoms similar to those which now would name Crohn's Disease can be found in many descriptions of ill people before the $19^{\text {th }}$ century: Around 1850 King Alfred, so called England's darling, suffered from an illness which caused pain on eating as well as abdominal discomfort [5]. These symptoms started at the age of 20 and were reported along many years of his life [5]. At that time of course no concepts about pathophysiology or disease entities did exist. Therefore, his symptoms were regarded to be caused by witchcraft, which was a frequent explanation for symptoms that could not be explained otherwise. As another scientific concept of diseases existed at that time, witchcraft was the explanation for most of the malconditions of the body and it until the $17^{\text {th }}$ century medicine and magical thinking remained connected [6].

In the $17^{\text {th }}$ century- despite still being illegal in many places - autopsy became a part of medical education and research at many universities [7,8]. In 1612 a doctor performed an autopsy on a young boy who had complained of abdominal pain and finally had died with symptoms of abdominal cramps and rectal bleeding. Upon autopsy the doctor noted ulcerations in the intestine which was the only pathological conditions he could find in that boy [9]. In a historical overview published in 2001, Kirsner mentions a large number of individual patients reports on symptoms that could retrospectively interpreted as Crohn's disease [9]. 
In his monographic book on regional ileitis, originally published in February 1949 in New York, Burrill B. Crohn himself gave several examples of historical descriptions of symptoms that might have be interpreted as Crohn's disease [10]. Crohn mentions, that in 1813 Combe and Saunders reported before the Royal College of Physicians in London on "A Singular Case of Stricture and Thickening of the lleum" in a patient they did autopsy [11](cited according to [10]). The original citation is "The lower part of the ileum, as far as the colon, was contracted for the space of three feet to the size of a turkey quill" [10]. In 1828 John Abercrombie also reported a case of regional ileitis. "A girl, age 13, about a year before her death (1814) began to be afflicted with pain of the abdomen and frequent vomiting. The caput coli the inches along the ascending colon and the lower end of the ileum to the extent of about eighteen inches, was distended, thickened in the coats, externally of a reddish color and internally covered by numerous well-defined ulcers, varying in size from a diameter of a split pea to that of a sixpence" [12] (cited according to [10]). As diagnostic tools were very limited and frequently patients could not make it to the hospitals at that time it is obvious that only case description but no systematic investigations were possible. In general, "systematic medicine" had not been initiated yet. Medicine overall was "anecdotic" at those times and case descriptions were published frequently to share unknown findings.

At the beginning of the $20^{\text {th }}$ century the "concept of disease", as we have it now, began to evolve [13]. This was associated with a systematic approach to collect similar cases of symptoms and to define "new" diseases. In Germany Braun in 1901 quoted five cases of non-specific inflammatory granulomata of the intestine [14]. In 1920 Tietze had reported in 2 cases of typical regional ileitis [14]. Further cases of regional ileitis were published by Korte in 1921, Landois in 1923, Konjetzny in 1932 and by Fischer and Lurmann (all cited according to [14]). According to the monography by Burrill B. Crohn, the paper by Fischer and Lurmann included the description of three cases of typical regional or terminal ileitis [14]. The cases were discussed before the German congress where it turned out that there was experience on similar cases by many surgeons as Haderer, Gisbergs, Peters, Anschütz, Fenster and others [14].

In 1913 T. Kennedy Dalziel reported in the British Medical Journal that he had treated thirteen patients who had suffered from intestinal obstruction [15]. Unfortunately the treatment was not very successful, because on autopsy he found that all thirteen patients 
had inflamed ileal and colonic areas [9]. At that time microscopic examination was possible. On the microscopic examination of the tissue he found a transmural inflammation with ulcers and fibrotic areas [15]. Dalziel found similarities Johne's mycobacterial intestinal disease of cattle to be intriguing and was the first to suspect that the intestinal inflammation might be caused by atypic mycobacteria. However, Dalziel's manuscript was not well perceived and it became forgotten.

Further case descriptions of ileitis and non-infectious granuloma were published in the US by Coffen in 1925 or Mock in 1931 [9]. Finally in 1923, Berg, Oppenheimer and Ginzberg, who were surgeons at the Mount Sinai Hospital in New York collected twelve patients with similar symptoms not caused by any known disease [9]. In 1930 Burrill B. Crohn reported similar findings in two patients and called it "terminal ileitis". On the suggestion of Paul Klemperer they combined their cases and published them in the Journal of the American Medical Association, JAMA, in 1932 [1]. The disease was first named terminal ileitis. The article was published at the time when the medical community was receptive to new findings. But at that time the description was not revolutionary or completely innovative. It was based on the description of many colleagues before.

When Crohn and colleagues published their well perceived report on this "new" disease other colleagues easily collected similar cases. In 1935 Binney collected 267 cases from the existing literature taking together all the case reports that had been published before [16]. In 1939 Ravdin and Johnston carried together 393 cases from the existing books and journals [14].

Immediately a discussion was initiated whether those published cases could be summarized under one disease or would represent different diseases. At this point it is important to note, that the discussion whether Crohn's disease is "one disease" or "several diseases" is obviously not new but was there right after the first comprehensive description by Burrill B. Crohn. Reasons for the discussion were that location of inflammation varied between different patients and that either the terminal ileum, the colon or both or other parts of the intestine could be inflamed. The occurrence of the disease had various areas of the intestines immediately caused a discussion whether regional ileitis would be a clinical but not a pathologic entity. The basic concept of being a clinical but not pathologic entity is still 
found in the notions that Crohn's disease might be several diseases and not just one which was brought up by several well-known experts in recent years.

\section{Initial Concepts of Pathophysiology}

Despite the huge development of insights into pathophysiological mechanisms some principal concepts on the pathophysiology of Crohn's disease came into existence right after the article published by Crohn, Ginzburg and Oppenheimer. As outlined in the monography by Burrill B. Crohn, Meyer and Rosi pointed to the involvement of the mesentery especially in fistula formation [17]. They already suggested in the 30ies that the mesentery and the mesenteric fat could play an important role. The blockade of ileum lymphatics was regarded to be of pathophysiological importance [17]. Also the appendix was thought to be possibly an important etiologic factor [17]. Burrill B. Crohn himself was convinced that regional ileitis was caused by mycobacterium avium subspecies paratuberculosis (MAP). He found that "Johne's disease in cattle has many resemblances to human ileitis in its anatomic configuration". However, Crohn he had to admit that true cause of terminal ileitis was unknown despite the efforts to identify certain bacterial or specific age and contributing factor [18]. Of course histological features such as the granuloma and also morphological findings of the inflamed ileum reminded many physicians of intestinal tuberculosis. In fact, still there is well known a risk to misclassify intestinal tuberculosis as Crohns' disease.

Further attempts were undertaken to identify the cause Crohn's disease in those days. In early experiments the bowel wall of the ileum of affected patients and mesentery lymph nodes were homogenized and inoculated into guinea pigs or rabbits - they did not cause any signs of Crohn's disease in those animals [18]. However it was argued, that the bacterial caused agent might be species specific and simply not able to cause infection in these animals. At that time microbiology was very successful and could identify the causative agents for many diseases for which pathophysiology had not been clear over centuries. As mentioned Crohn and others found the similarities of symptoms of the human disease to Johne's disease in cattle, caused by mycobacterium avium ssp. paratuberculosis. However, reasoning by analogy or via similarities usually is not regarded to be logic-based and is not accepted as an appropriate scientific method. 
Burrill B. Crohn had further explanations. In the book published in 1949 he states that in his own experience "in spite of an initial skepticism, there seems to be sufficient basis for associating trauma and ileitis, in the relationship of cause and effect. This conclusion is based upon experience....." [18]. He seems to be convinced that a trauma could cause regional ileitis. All the cases he mentions in the book had some sort of trauma such as being hit by a moving truck, being thrown across the alley of a bus, being involved in an automobile accident or being involved in an explosion of a bomb in the army [18]. In those cases Crohn's disease appeared weeks after the initial trauma.

On the other hand Burrill B. Crohn already realized that there were familial incidents of ileitis and regarded this as a possible ecological factor. He states "regional ileitis or enteritis occurs in multiply instances in intimately blood related members of a family sufficiently often to call for attention because herein may lay clue, if not to etiology, at least to familial predisposition." (Page 21) [18]. Crohn assumed a familial predisposition. However, he thought that the familial predisposition was with respect to a so far undiscovered and unrecognized infectious agent that would spread within certain families. This indicates that starting with the early descriptions of the disease there was always the search for an infectious causative agent. This might also shed light onto the new hype on the microbiome as being "the" causative actor. As no single infectious agent could be identified now the whole community of intestinal microbes is "accused" to cause a disease. The research on the microbiome appears not to be revolutionary under this view. It is a logical consequence of those existing "pre-ideas" on infectious agents that cause terminal ileitis.

Interestingly it was regarded unlikely in the early descriptions that any social factors play a role in the pathophysiology or incidence of the disease. Patients initially were described as phlegmatic and calm but usually sensitive, emotional and excitable (page 30) [18]. Crohn states that "my own observations do not impress me with the fact that the ileitis case is much different than a control group of the population." Crohn finds that "all classes of society are affected equally by ileitis" (page 31)[18]. He further states "all races and climes seem represented in this disease since the literature from all over the world contains publications of cases (Africa, India, Sweden, Puerto Rico, East Africa, South America)" (Page 32) [18]. It is interesting, that the higher prevalence in North America and Scandinavia was not recognized at that time. From the low number of cases it is obvious that it was 
impossible to conclude on environmental factors. Those studies always require large case numbers and proper statistics.

\section{Is IBD a "syndrome"?}

Frequently there is a notion that Crohn's disease and ulcerative colitis are not diseases but "syndromes". To clarify this issue it may be important to first look into the definition of syndrome and disease. In medicine in general a syndrome is thought to be the association of several clinical recognizable features, signs and symptoms (reported by the patient) or characteristics that often occur together. Usually the presence of one or more of those features then guides clinicians to the possible presence of the others. However syndromes may have a range of possible etiologies. Perhaps this is the reason why Crohn's disease and ulcerative colitis are called "syndromes". An example may be Parkinson's syndrome that has a wide range of symptoms. Parkinson's syndrome may be caused by Parkinson's disease. On the other hand certain drugs or certian other diseases also may cause Parkinson's syndrome. In analogy to Crohn's disease this would mean that there is a Crohn's syndrome and that Crohn's disease only is a part of this Crohn's syndrome and that certain drugs or other causes may mimic the clinical appearance of Crohn's disease. However at present, we have no evidence that any drug or any other conditions would mimic Crohn's disease.

On the other hand, a disease is described as "any impairment of normal physiological functions which then produces characteristic symptoms". Any deviation from or interruption of the normal structure function of a body part, organ or system that is manifested by a characteristic set of symptoms and signs is called a disease [19]. However for the definition of a disease etiology, pathology and prognosis may well be unknown and knowledge on those factors os not necessary. The finding of the pathophysiology, the definition of etiological pathways and further insights into pathology do not "change" the disease. Those factors are not relevant for the definition. Therefore, it is unlikely that unrevealing of pathophysiological factors such as genetic susceptibility may change our understanding of Crohn's disease.

We further - and this is important to note - do not need an exact definition of a disease. This is similar to the definition of an object we use in our normal lives as such as a chair. There 
are numerous different chairs with different forms and different use. There is the classical chair with four legs; however, there are chairs with just one leg. There are chairs with normal forms, chairs with curious forms. There are chairs on which one cannot even sit because they are huge and just stand in front of a furniture shop. It is obvious that even a simple item such as a chair cannot be exactly defined by form, by function or by use. As we are unable to clearly define such a simple thing, it is not unusual or surprising that we are unable to define clearly such a complicated thing as Crohn's disease. The lack of a definition does not mean that this is a "syndrome" or something we could not have a shared opinion on.

In his famous book "Philosophical Investigations" the philosopher Ludwig Wittgenstein regularly referred to the concept of so called "language games" [20]. Wittgenstein in fact rejected the idea that words or terms in language have a direct connection to reality. One of his most important arguments was that concepts do not need to be clearly defined to be meaningful and to be used in an intersubjective exchange [20]. Concepts and meanings of words are not separated from each other by sharp boundaries, but blend into one another. Thus, the lack of a "specific definition" of Crohn's disease does not mean a disadvantage or shortcoming in the understanding of the disease.

It might be helpful to compare the concept of Crohn's disease to a concept that is well accepted and well known such as coronary heart disease (table 1). The etiology of both diseases is multifactorial and genetic risk factors and susceptibility factors have been identified for both Crohn's disease and coronary heart disease. On the other hand there is clear scientific evidence that environmental factors contribute to both Crohn's disease and coronary heart disease. Without those environmental factors the genetic risk is not sufficient to manifest a disease. Symptoms for both coronary heart disease and Crohn's disease are variable and no unique definition of symptoms exists. Also the outcome of both Crohn's disease and coronary heart disease and the clinical course are highly variable. Therapy for both disease may either be conservative or via surgery or a combination of both. 
Coronary Heart Disease as example:

\section{Crohn's Disease}

Etiology

Genetic risk

Environm. factors

Variable symptoms

Outcome

Therapy multifactorial

$+$

$+$

$+$

variable

conserv./surgery
Coronary Heart Disease

multifactorial

$+$

$+$

$+$

variable

conserv./surgery

Table 1: Comparison of Crohn's disease and coronary heart disease. Both are regarded as a disease and not as a "syndrome".

With respect to those categories such as etiology, genetic risk, environmental factors, symptoms, outcome and therapy Crohn's disease and coronary heart disease are similar. They represent a complex of symptoms, a complex of pathophysiological pathways and nevertheless they are regarded as one disease because this concept makes sense in the present situation of medical science. It is unlikely that new insights into one of those factors such as environment or genetic risk will completely change the concept of those diseases. 
Why do pathophysiological concepts that have never been proven (or even have failed) still have followers?

The concept that diseases are caused by an infectious agent was very successful in the $19^{\text {th }}$ and early $20^{\text {th }}$ century. Subsequently an infectious cause was also searched for in the pathogenesis of IBD. Different bacteria or infectious agents have been accused to cause Crohn's disease in recent decades. Amongst those infectious agents were mycobacteria avium subspecies paratuberculosis [21-23], viruses [24-27], enteroinvasive E. coli [28-30] and many more. For none of those infectious causes sufficient evidence has been found (which may be seen differently by supporter of those concepts).

As an example we may have a closer look on mycobacterium avium paratuberculosis (MAP) and the theories that it might cause Crohn's disease. Despite the fact that neither Burrill B. Crohn nor any other investigator following him could provide unequivocal evidence that MAP causes Crohn's disease there are still strong believers in this theory such as the "International Association of Paratuberculosis". If we have a closer look at the pathogenesis of Crohn's disease and connections to MAP, we first have to question whether there is any evidence from epidemiology. In fact most epidemiological data point to a lack of connection between MAP and Crohn's disease. Crohn's disease in USA is not preferentially found in the states in which of Johne's disease in cattle occurs most frequently. In fact, MAP infections are found in immuno-compromised patients such as HIV patients with low lymphocyte counts. In contrast, in IBD we suppress lymphocyte counts and decrease those cells by drugs such as azathioprine. We assume that inflammation in IBD patients is successfully controlled by immunosuppressants, which is in clear contradiction to the MAP theory. Using immunosuppressives would mean that we put patients at risk to develop more severe mycobacteria infections.

Furthermore, the fact that MAP DNA is found in inflammatory lesions of IBD patients does not mean that the bacterium is of any causative effect. DNA of many other bacterial species also is found in inflammatory lesions of this patient group. It is not logically or scientifically sound to conclude from a simple association of findings to a causative relationship. Nevertheless investigators on the MAP field are quite convinced about their theory and can never be convinced by the arguments mentioned above. 
At this point we can have a closer look at Sir Carl Popper's "Logik der Forschung" in which he analyzes scientific reasoning [31]. One of his basic assumptions is that scientific theories cannot be proven by experiments. For example the fact that I only observe white swans in Switzerland based on 873 single observations does not mean that there are no black swans somewhere else in the world. This means that no number of positive outcomes at the level of experimental testing can confirm a scientific theory [31]. Popper states that scientific theories are always hypothetical and generated by creative imagination in order to solve problems that have arisen in specific historical cultural settings (for example IBD as an autoimmune disease, IBD as an innate immune disease and so on). However according to Popper a single counter-example is logically decisive: It identifies the theory from which the implication was derived from as being wrong. Thus the theory should no longer be followed.

According to Popper science would work like this: When I have a hypothesis (i.g. "MAP infection causes Crohn's disease") I perform experiments to falsify this hypothesis (e.g.: "Do I find patients with IBD without MAP presence?"). As long as there are no contradictable results the theory or hypothesis is valid (this would mean if there are any patients without MAP in the mucosa the theory is falsified). As evident from recent publications there are many patients where we cannot find MAP in the intestinal mucosa. This would mean that the theory is falsified.

Popper tried to find "deductive conclusions in an inductive direction". He made clear that inductive reasoning comes from a specific event (experiment) and wants to conclude on a general rule. This is not logically plausible as we would have to proof it for all time and time points and points in space. However, with deductive reasoning we generate first hypotheses and general rules that we try to falsify by specific events or experiments. As soon as we have falsified such a general rule we have to admit it and try to find better hypotheses.

As mentioned above there are many counter-examples to the theory that MAP causes Crohn's disease. So why are there still studies, discussions, presentations and researchers working on it? From a philosophical point of view it may be said that either Popper is wrong or MAP-believers are wrong or both are wrong. 


\section{Do think-collectives guide our research on the pathophysiology of IBD?}

Ludwik Fleck, a medical doctor and philosopher born in Poland developed in the 1930's the concept of a "think-collective" or "thought-collectives". He published a book called "Entstehung und Entwicklung einer wissenschaftlichen Tatsache (Einführung in die Lehre von Denkstil und Denkstilkollektiv)" [32]. Ludwik Fleck's concept explains how and why scientific ideas change over time or remain stable. Researchers are locked in "thought-collectives", "concept-groups" or "thought-styles". Fleck explains this concept convincingly with the history of the discovery of syphilis as an infectious disease. The symptoms of syphilis always had been described very conclusive in the past - and after stopping to believe in witchcraft, scientists always were looking for a causative agent in the blood of the patients. This can be followed back even to Aristotle who tried to define different characteristics of the blood for different diseases. Despite the fact that no causative agent could be found in the blood of patients for centuries this concept was not abandoned and after thousands of failed experiments it was finally successful with the discovery of Trepponema pallidum.

In reality scientific theories are not abandoned of left when they are falsified or cannot be proven. Ludwik Fleck calls this principle "self-immunization" of thought-collectives against falsification. Ludwik Fleck defines a thought collective to be "a community of persons mutual exchanging ideas and maintaining intellectual interaction" (Page 39)[32]. He gives examples illustrating that thought collectives have their own (more or less stable) structure. Sometimes they are relatively small esoteric circles of experts and much bigger circles of teachers and scholars applying for membership. The beliefs and opinions common to the members of a thought collective are called "thought-style" (e.g. "IBD is a T-cell mediated autoimmune disease" or "IBD is a defensin deficiency"). Usually there is an agreement on what members of a thought collective consider evident and what method are adequate for further research (page 99) [32]. Researchers are socialized into a thought-collective usually by dogmatic teachers that have success in a scientific community with their theories. Students hearing lectures from those teachers go through a process of "initiation", which introduces them into the circle where everybody thinks in the same way. Different thoughts are contradictory statements are only possible on particular minor applications of the basic theory but not about basic principles. Thus, what they believe seems "obvious" or "evident" to them (e.g. "Crohn's disease is a defensin deficiency"). 
In contrast to Karl Popper, Ludwik Flack has a complete different concept about how hypotheses are generated. As mentioned, Popper suggested that first there is a hypothesis and research is determined to falsify it. If anybody has ever worked in a scientific lab he or she definitely knows that this is not the way how scientists work in reality. The question is where do those hypotheses come from? Popper cannot answer this question. He thinks that hypotheses come by intuition or fantasy. However, this would mean that there are random and perhaps not based on any evidence from reality. So do they perhaps come from inductive conclusions? This is one of the major weaknesses in Popper's theory. Fleck's suggestions are much more realistic: In thought-collectives there are so called "pre-ideas" that guide generation of hypotheses [32]. For example the concept of "dyscrasia" which can be followed back to Aristotle saying that "diseases are caused by disturbances of body fluids". Another pre-idea that has successfully guided modern research is that "diseases are caused by infectious agents" (such as viruses or MAP in the case of Crohn's disease). A similar pre-idea or concept that guided the generation of hundreds of hypotheses was that "inflammatory diseases are either infections or autoimmune diseases". Those concepts are usually very successful. It is only natural that they are applied to all diseases that are so far unexplained. Subsequently the conclusion can only be that pre-ideas that are - without being outspoken - present in the scientific community determine our ability to generate hypotheses - and that the latter are not completely rational.

\section{Why do concepts on IBD pathogenesis change over time?}

In recent decades we have experienced several changes in the concepts on the pathophysiology of Crohn's disease or ulcerative colitis. Fifteen to twenty years ago the concept of a typical autoimmune disease with a T-cell mediated pathology was common. Research and concepts moved on to genetics and tried to define especially Crohn's disease as a "genetically-caused" disease. However in the meantime we are aware that genetics may only explain a minority or at least less than $50 \%$ of the cases of IBD. So the pathology concepts were modified by the affected pathways that genetic analysis had identified and IBDs were called innate immune diseases. Parallel there was another development calling IBD barrier diseases where the intestinal mucosa is not sufficiently able to keep the intestinal 
microbiota away from invading the body. In the meantime, and that is the most recent hype, the focus has changed to the microbiota and luminal content of the gut.

It has to be kept in mind that all those developments were not inherent in the logical development of theories. All those changes and hypothesis were caused by the techniques of research available at the respective times. When we were able to characterize T-cells by flow cytometry and surface marker analysis and to discriminate certain sub-populations of Tcells, we were investigating into auto-immunity and T-cell mediated factors as cause of IBD. New sequencing techniques and ability to study genome-wide associations made it possible to study the genetics of IBD. We gained insights, however the concept that there is a familiar or genetic association in IBD especially in Crohn's disease was already established by Burrill B. Crohn (see above). We have gathered more specific information and know now which genes are involved. The general principle of genetic association however, had already been assumed when the disease was described initially. And finally, when innate immune processes were better understood, IBD became an "innate immune disease". As we now have the capacity to do pyro-sequencing of intestinal bacteria, the microbiota is in the focus.

Obviously the technique we have available at a certain time always influences our view on disease pathophysiology. It is important to keep in mind that this is not an independent development that is only caused by better insights into disease pathophysiology. The main determinant of the way we approach pathophysiology of IBD is determined by the technical tools we have available.

\section{How can the paradigms that generate new hypothesis be changed?}

In 1962 Thomas S. Kuhn published a famous book called "The structure of scientific revolutions" [33]. Thomas S. Kuhn outlines that science undergoes periodic "paradigmshifts" instead of progressing in a linear and continuous way. Competing paradigms are frequently found to be "incommensurable"; that is, they are competing accounts of reality but they cannot be coherently reconciled. Thus, what we call science and rationality at a specific point in time can never rely on full "objectivity". We must always account for historico-social contexts, subjective perspectives and availability of technical tools. Indeed if we look at scientific meetings on IBD, in IBD pathophysiology research there still thought- 
collectives that have mainly incommensurable thoughts (Figure 1):

- there is the "T-cell/adaptive immunity/IL-12, IL-17, IL-23/T-rec-community"

- there is the "barrier defect /epithelial cell -community"

- there is the "innate immunity-community"

- there is the "infectious disease- community"

- there is the "defensine deficiency-community"

- there is the "genetic caused-community"

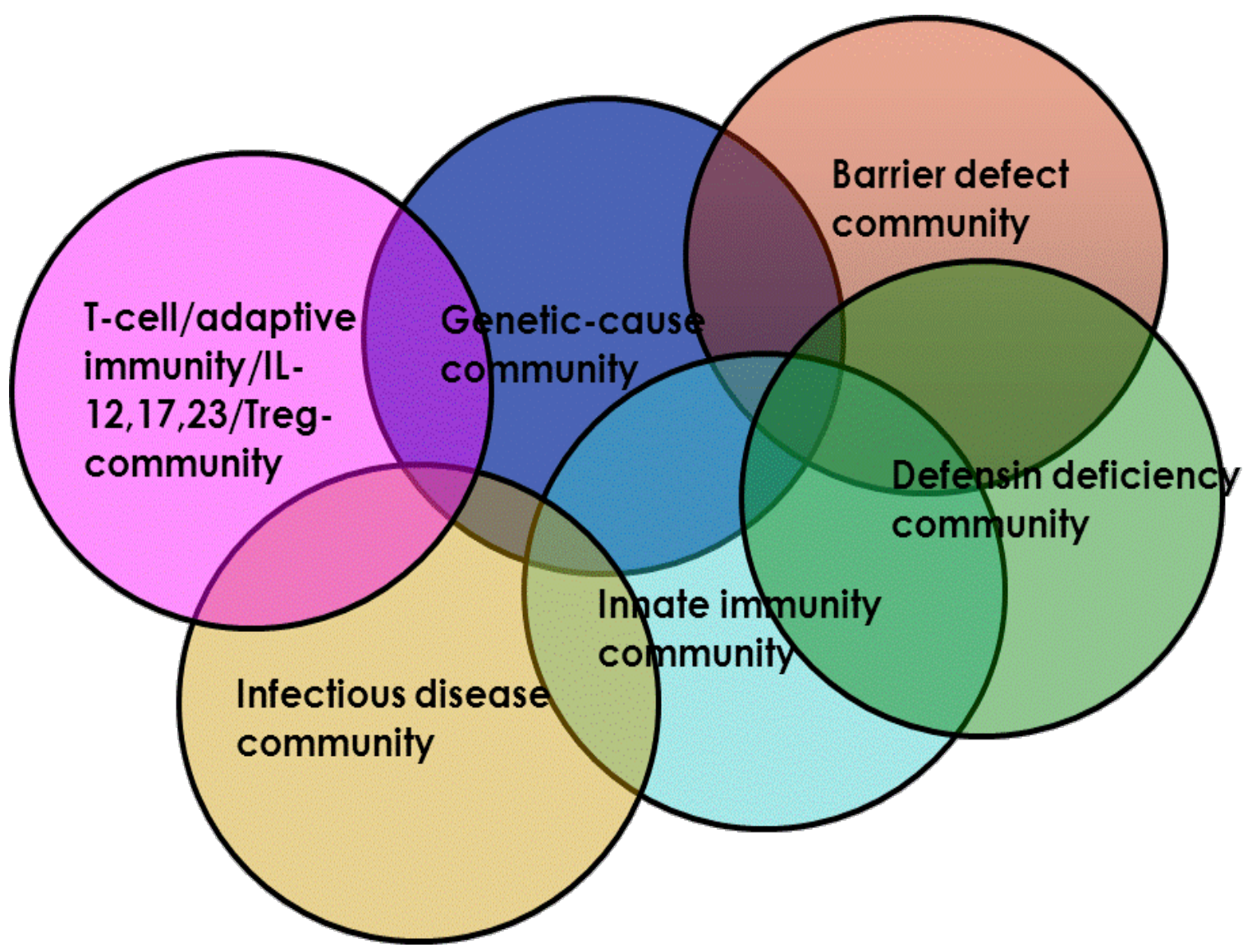

Figure 1: Different "thought-styles" or "think-collectives" contribute hypotheses to the concepts on IBD pathophysiology. There are overlaps; however, some concepts are rather incommensurable. 
Due to these incommensurable thought-stiles and thought-collectives we will never have something such as a "single, simple, unified hypothesis on IBD pathophysiology".

\section{Conclusion}

Subsequently the bad news about IBD pathophysiology from a modern view of theory of science-philosophy is: Despite we meet in scientific symposia and we discuss our hypotheses, despite we are all good scientists and probably nice guys and despite we want to unravel the pathophysiology of IBD and understand each other, we have been socialized into separate thought-collectives maintaining separate thought styles. Therefore we will never completely understand each other. We also will never completely convince each other (probably we will not even partially convince each other). And we will never come up with ONE concept on IBD pathophysiology everybody will agree to.

The good news about IBD from a modern view of theory of science-philosophy is: There is no logical stringent research (e.g. "true" critical rationalism as Popper suggested) and as our concepts on IBD pathophysiology depend on the socio-historic context we all can go on staying with our thought-style as no one can be proven to be definitively wrong.

This means we are all (relatively) right! 


\section{References}

1 Crohn BB, Ginzburg L, Oppenheimer GD: Regional ileitis: A pathological and clinical entity. JAMA 1932:1323-1329.

2 Baron RJ: An introduction to medical phenomenology: I can't hear you while i'm listening. Ann Intern Med 1985;103:606-611.

3 Rosenberg CE: Disease in history: Frames and framers. Milbank Q 1989;67 Suppl 1:1-15.

4 Rosenberg CE: The history of disease: Now and in the future. Henry E Sigerist Suppl Bull Hist Med 1982:32-36.

$5 \quad$ Craig G: Alfred the great: A diagnosis. J R Soc Med 1991;84:303-305.

6 Wynn R: Saints and sinners: Women and the practice of medicine throughout the ages. JAMA 2000;283:668-669.

7 Clark MJ: Autopsy. Lancet 2005;366:1767.

8 Hirt M, Kovac P: History of forensic medicine-the second part. The autopsy in the middle age and the renaissance. Soud Lek 2005;50:32-37.

9 Kirsner JB: Historical origins of current ibd concepts. World J Gastroenterol 2001;7:175-184.

10 Crohn BB: Regional ileitis. Delanco, New Jersey, Gryphon Editions, 1942, pp 2ff.

11 Combe C, Saunders H: A singular case of stricture and thickening of ileum. Med Tran of Roy Coll Physicians London 1813;4:16.

12 Abercrombie J: Pathological and practical researches of the stomach. The intestinal tract, and other viscera. Edinburgh, Waugh and Innes, 1828.

13 Najman JM: Theories of disease causation and the concept of a general susceptibility: A review. Soc Sci Med Med Psychol Med Sociol 1980;14A:231-237.

14 Crohn BB: Regional ileitis. Delanco, New Jersey, Gryphon Editions, 1942, pp $3 \mathrm{ff}$.

15 Dalziel TK: Chronic interstitial enteritis. Br Med J (Clin Res), 1913:1068.

16 Binney H: Regional ileitis. Ann Surg 1935;102:695.

17 Crohn BB: Regional ileitis. Delanco, New Jersey, Gryphon Editions, 1942, pp 6ff.

18 Crohn BB: Regional ileitis. Delanco, New Jersey, Gryphon Editions, 1942, pp 12ff.

19 http://www.thefreedictionary.com/disease:

20 Wittgenstein L: Philosophische untersuchungen. Kritisch-genetische edition. Frankfurt, Wissenschaftliche Buchgesellschaft, 2001.

21 Gitlin L, Borody TJ, Chamberlin W, Campbell J: Mycobacterium avium ss paratuberculosisassociated diseases: Piecing the crohn's puzzle together. J Clin Gastroenterol 2012;46:649-655.

22 Over K, Crandall PG, O'Bryan CA, Ricke SC: Current perspectives on mycobacterium avium subsp. Paratuberculosis, johne's disease, and crohn's disease: A review. Crit Rev Microbiol 2011;37:141-156.

23 Sartor RB: Does mycobacterium avium subspecies paratuberculosis cause crohn's disease? Gut 2005;54:896-898.

24 Ghosh S, Armitage E, Wilson D, Minor PD, Afzal MA: Detection of persistent measles virus infection in crohn's disease: Current status of experimental work. Gut 2001;48:748-752.

25 Robertson DJ, Sandler RS: Measles virus and crohn's disease: A critical appraisal of the current literature. Inflamm Bowel Dis 2001;7:51-57.

26 Rhodes J, Freedman AR: Measles, mycobacterium paratuberculosis and crohn's disease. Ital J Gastroenterol Hepatol 1999;31:255-257.

27 Wakefield AJ, Ekbom A, Dhillon AP, Pittilo RM, Pounder RE: Crohn's disease: Pathogenesis and persistent measles virus infection. Gastroenterology 1995;108:911-916.

28 Small CL, Reid-Yu SA, McPhee JB, Coombes BK: Persistent infection with crohn's diseaseassociated adherent-invasive escherichia coli leads to chronic inflammation and intestinal fibrosis. Nat Commun 2013;4:1957. 
29 Nickerson KP, McDonald C: Crohn's disease-associated adherent-invasive escherichia coli adhesion is enhanced by exposure to the ubiquitous dietary polysaccharide maltodextrin. PLoS One 2012;7:e52132.

30 Greenhill C: Crohn's disease: Adherent-invasive escherichia coli target peyer's patches. Nat Rev Gastroenterol Hepatol 2011;8:246.

31 Popper K: Logik der Forschung. Oldenbourg Verlag

32 Fleck L: Entstehung und Entwicklung einer wissenschaftlichen Tatsache: Einführung in die Lehre vom Denkstil und Denkkollektiv. Frankfurt, suhrkamp taschenbuch wissenschaft

33 Kuhn TS: The structure of scientific revolutions. Chicago, University of Chicago Press, 1996. 